\section{Effects of different rearing temperatures on muscle development and stress response in the early larval stages of Acipenser baerii}

Lucia Aidos, ${ }^{1}$ Luisa M. Pinheiro Valente, ${ }^{2,3}$

Vera Sousa, ${ }^{2}$ Marco Lanfranchi, ${ }^{4}$

Cinzia Domeneghini, ${ }^{1}$

Alessia Di Giancamillo ${ }^{1}$

${ }^{1}$ Department of Health, Animal Science and Food Safety, University of Milan,

Italy

${ }^{2}$ ICBAS-Instituto de Ciências

Biomédicas de Abel Salazar, University

of Porto, Portugal

${ }^{3}$ CIMAR/CIIMAR-Centro

Interdisciplinar de Investigação

Marinha e Ambiental, Terminal de

Cruzeiros do Porto de Leixões,

Matosinhos, Portugal

${ }^{4}$ Società Naviglio Agricola SS, Goito, Italy

\section{Abstract}

The present study aims at investigating muscle development and stress response in early stages of Siberian sturgeon when subjected to different rearing temperatures, by analysing growth and development of the muscle and by assessing the stress response of yolk-sac larvae. Siberian sturgeon larvae were reared at $16^{\circ} \mathrm{C}, 19^{\circ} \mathrm{C}$ and $22^{\circ} \mathrm{C}$ until the yolk-sac was completely absorbed. Sampling timepoints were: hatching, schooling and complete yolk-sac absorption stage. Histometrical, histochemical and immunohistochemical analyses were performed in order to characterize muscle growth (total muscle area, TMA; slow muscle area, SMA; fast muscle area, FMA), development (anti-prolif erating cell nuclear antigen -PCNA or anticaspase) as well as stress conditions by specific stress biomarkers (heat shock protein 70 or 90, HSP70 or HSP90). Larvae subjected to the highest water temperature showed a faster yolk-sac absorption. Histometry revealed that both TMA and FMA were larger in the schooling stage at $19^{\circ} \mathrm{C}$ while no differences were observed in the SMA at any of the tested rearing temperatures. PCNA quantification revealed a significantly higher number of proliferating cells in the yolk-sac absorption phase at $22^{\circ} \mathrm{C}$ than at $16^{\circ} \mathrm{C}$. HSP90 immunopositivity seems to be particularly evident at $19^{\circ} \mathrm{C}$. HPS70 immunopositivity was never observed in the developing lateral muscle.

\section{Introduction}

Sturgeons (Acipenseriformes) constitute one of the most ancient groups of the Osteichthyes, and it comprises 25 species that are distributed throughout the Northern Hemisphere, Eurasia and North America. ${ }^{1}$ During the latest two hundred years, there was a severe worldwide decrease of the sturgeon stocks and, currently, most of the sturgeon species are in the Apendix II of the Convention on International Trade in Endangered Species of Wild Fauna and Flora (CITES). Sturgeon farming is, therefore, important not only for the production of caviar and meat but also because it may contribute to the natural stocks protection. Among the sturgeon species, one of the most commonly used in aquaculture is the Siberian sturgeon (Acipenser baerii) which is currently reared in 22 countries presenting a total production of about 8800 tonnes per year.

Production of high quality fish larvae is of great importance in aquaculture: even if large amounts of larvae hatch from artificially fertilized eggs, mortality in the early stages still remains quite high or present a high, not expected variability, or frequent rates of deformities occur. ${ }^{2}$ For the aquaculture industry it is, hence, of vital importance to produce high quality and healthy juveniles. Embryonic and larval development in bony fish is strongly influenced by environmental factors, mainly by temperature and dissolved oxygen, as it is in adults. In teleost species larvae, the environmental factors determine the myogenesis rate, the subcellular structure of the muscular fibres, the gene expression models and the number and dimension of muscle fibres. In studies performed in seawater larval species, Conceicao et al. ${ }^{3}$ found that environment has also an influence on the efficiency of the contractile proteins deposition. Larval development of sturgeon still represents an extremely difficult stage, often characterised by high mortality rates. ${ }^{4}$ In intensive fish farming, aquatic species are continuously subjected to several environmental discomfort conditions such as handling, feed composition, confinement, density, hierarchical relations, as well as water quality variations in its both abiotic $(\mathrm{pH}$, dissolved oxygen, temperature, pollutants, etc.) and biotic (plankton, bacteria, etc.) components that, as a whole, may lead to environmental stress occurrence. ${ }^{5}$ Farmed sturgeon is, as well, subjected to many environmental stressors, like crowding, handling procedures that precede transportation and/or medical treatments, temperature variations, and may be of great interest for
Correspondence: Alessia Di Giancamillo, Department of Health, Animal Science and Food Safety, University of Milan, Via Trentacoste 2, 20134 Milano, Italy. Tel. +39.02.50315741 - Fax: +39.02.50317914. E-mail: alessia.digiancamillo@unimi.it

Key words: Sturgeon larvae; muscle development; temperature; heat shock protein; proliferating cells; histometry.

Contributions: LA, ADG, $\mathrm{CD}$ designed the project; LA, ADG, ML performed the in vivo experimental procedures; LA, ADG, performed the laboratory analyses; LA, VS, LMPV, performed the histometrical analyses; LA, ADG, CD, performed the statistical analyses and wrote the paper. All authors contributed to the different draft versions of the manuscript and approved the final manuscript.

Conflict of interest: The Authors declare no conflict of interest.

Acknowledgments: This research was in part supported by grants of Fondazione CariploItaly to Cinzia Domeneghini. The authors wish to thank the sturgeon farm "Società Naviglio Agricola" for the supply of the fertilized eggs utilized for this study.

Received for publication: 14 September 2017 Accepted for publication: 27 October 2017.

This work is licensed under a Creative Commons Attribution-NonCommercial 4.0 International License (CC BY-NC 4.0).

CCopyright L. Aidos et al., 2017

Licensee PAGEPress, Italy

European Journal of Histochemistry 2017; 61:2850 doi:10.4081/ejh.2017.2850

the fish farmers to identify the stress effects of the environmental conditions.

A better understanding of the effects of stress could give additional information regarding the environmental causes of the observed discrepancies ${ }^{6,7}$ in growth rates among different stocks, with important positive consequences again on sturgeon farming and production. Skeletal muscle constitutes the edible part of the fish. Studies of muscle growth since precocious ages (yolk sac) are therefore important for an optimal development and assessment of fish farms for both protective and productive aims.

Heat shock proteins (HSP) are a family of highly conserved proteins that are expressed in response to several biotic and abiotic stressors, in such a way to be potentially identified as damage biomarkers. An intense stress, not only thermal in its nature, induces a long-time expression of HSPs that are also known to play an important role in 
fish health. ${ }^{8,9}$ HSP70 assists the folding of emerging polypeptide chains, acts as a molecular chaperone, and intervenes on the repair and degradation of altered or denatured proteins. HSP90 has an active role in supporting various components of cell signalling, including the cytoskeleton, enzymes, and steroid hormone receptors. HSP70 expression has been studied in fish in relation to the exposure to pesticides, virus, metals and other toxic compounds. ${ }^{10-12}$

In fish larvae, the environmental stressors appear to affect a greater number of developing tissues than in adults. ${ }^{13}$ In addition, fish larvae may appear less tolerant than the adults to temperature variations, ${ }^{14}$ especially in critical moments of larvae development. According to Gisbert and Williot, ${ }^{15}$ after hatching, Siberian sturgeon shows benthic behaviour, then aggregates into schools. Normal schooling behaviour in this species can be used as a quality condition similarly in coregonid species. ${ }^{16}$ When the yolk-sac absorption is complete, schooling behaviour ceases, and most of the larvae is distributed on the bottom of the tank, or swimming along the tank walls and along the surface of water. ${ }^{17}$

There is increasing indication that early events may imprint an individual physiological memory leading to long-term effects on postnatal growth and physiological function, both in animals and humans. ${ }^{18}$ Environmental factors during the early stages may have a serious impact in an irreversible way in later development. ${ }^{18}$ It is, therefore, very important to optimize early rearing conditions to promote maximum growth.

The aim of the present study was, therefore, to monitor environmental stress occurrence and lateral muscle development in the early (until yolk-sac absorption) larval stages in Siberian sturgeon (Acipenser baerii), when subjected to one of the main stress factors occurring in fish farms: rearing temperature. The effects of the three different rearing temperatures as a possible stressor on muscle development in Siberian sturgeon larvae until complete yolk-sac absorption have been studied in this paper concerning: i) lateral muscle structural organization, and cell replication, in order to characterize lateral muscle growth; and ii) stress biomarkers.

\section{Materials and Methods}

\section{Fish larvae rearing and sampling}

The experiment was held during April 2016 at the Experimental Animal Research and Application Centre of Lodi, owned by the University of Milan. Siberian sturgeon fertilized (artificially inseminated) eggs were transported at $14^{\circ} \mathrm{C}$ from the "Società Agricola Naviglio" fish farm to the experimental unit $24 \mathrm{~h}$ after fertilization. Embryonic incubation was performed at the same temperature $\left(16.2 \pm 0.2^{\circ} \mathrm{C}\right)$ and hatching occurred 5 days after fertilization. Larvae were maintained in incubators (three per treatment); in one group temperature was maintained at $16^{\circ} \mathrm{C}\left(16.4 \pm 0.2^{\circ} \mathrm{C}\right)$ and, in the two other groups, temperatures were gradually shifted (one degree per hour) to either $19^{\circ} \mathrm{C} \quad\left(19.3 \pm 0.2^{\circ} \mathrm{C}\right)$ or $22^{\circ} \mathrm{C}$ $\left(21.9 \pm 0.2^{\circ} \mathrm{C}\right)$. Water temperature was daily monitored and kept under the fixed values for each incubator. Water was saturated with $\mathrm{O}_{2}$ throughout the trial $(>8 \mathrm{mg} / \mathrm{L})$ in all incubators, $\mathrm{pH}$ values were within the range described for this species in this stage of development. ${ }^{15}$ Eggs and larvae were exposed to an artificial photoperiod regime of 12L:12D. Along the entire experimental period after hatching the larvae utilized the nutrients of their yolk sac and were not fed any exogenous food.

Moreover, sampling temporal points were chosen considering the important steps of Siberian sturgeon larvae behaviour development already described in the introduction: hatching (T0), beginning of the schooling phase (T1) and complete yolk-sac absorption phase (T2). Larval development period was calculated as days post-hatch (dph) until the yolk-sac full absorption (Figure 1). Survival rate was estimated by dead larvae daily recording.

This research was approved by the Ethic Committee of the University of Milan (OPBA_20_2016).

\section{Histometry, histochemistry and immunohistochemistry}

For each sampling time point, 3 larvae per incubator were collected (total $n=9$ larvae per treatment) with a wide pipette and killed by over-anaesthesia with Ethyl 3Aminobenzoate, Methanesulfonic A (Sigma-Aldrich). Whole larvae were immediately fixed in $4 \%$ para-formaldehyde in $0.01 \mathrm{M}$ phosphate-buffered saline (PBS) $\mathrm{pH}$ 7.4 for $24 \mathrm{~h}$ at $4^{\circ} \mathrm{C}$, then dehydrated in a graded series of ethanol, cleared with xylene and embedded in paraffin. Serial transverse microtome sections ( $5 \mu \mathrm{m}$-thick) were obtained from each sample.

The sequential haematoxylin/eosin (HE) staining was performed for the evaluation of the structural aspects of the developing lateral muscle tissues and for histometry. The Trichrome Masson histochemical staining was applied according Goldner, ${ }^{19}$ in order to clearly distinguish developing connective and striated muscle tissues.

Briefly, the histometric variables as above detailed were measured on HEstained transversal body sections of individual fish larvae, at a peri-anal localization with the transverse sections conducted in a cranio-caudal direction with the first section rostral to the anus. Standard histometrical techniques were applied using an Olympus BX51 light microscope equipped with a DP-software program $\left(\right.$ Cell $^{\wedge} \mathrm{B}$, Basic Imaging Software, Olympus, Segrate, Italy) for describing: i) total muscle cross-sectional area (TMA); ii) red muscle area (slow muscle cross-sectional area, SMA); and iii) white muscle area (fast muscle cross-sectional area, FMA) at the three analysed developmental stages: hatching (T0), schooling (T1) and yolk-sac full absorption (T2).

Immunostaining on other transverse sections was performed to detect proliferating cell nuclear antigen (PCNA), caspase, HPS70 and HPS90, both the latter ones as in situ markers of the presence of environmental stressors. The applied immunohistochemical procedure has been previously described in detail (PCNA ${ }^{20}$; HSP70 and HSP9021). Briefly, endogenous peroxidase activity was blocked by incubating the sections in $3 \% \mathrm{H}_{2} \mathrm{O}_{2}$ in PBS. Nonspecific binding sites were blocked by incubating the sections in normal mouse serum (Dakocytomation, Milan, Italy). Mouse monoclonal anti-PCNA (dilution 1:200, clone PC10, Sigma-Aldrich, Milan, Italy), HSP70 (1:100; N27F3-4/Enzo LifeSciences, Farmingdale, NY, USA) and HSP90 (1:100, AC88/Enzo LifeSciences), as well as anti-caspase-3 (dilution 1:100, ab4051, ABCAM, Italy) antibodies were applied overnight at room temperature. Preliminary antigen retrieval for HSP70, HSP90 and caspase-3 was performed by heat, with a microwave treatment (for $5 \mathrm{~min}$ at $450 \mathrm{~W}$ in citrate buffer, $\mathrm{pH}$ 6). The used primary antisera were diluted with a $0.05 \mathrm{M}$ Tris- $\mathrm{HCl}$ buffered saline $\mathrm{pH} 7.4$ (TBS: 0.05 $\mathrm{M}, \mathrm{pH} 7.4,0.55 \mathrm{M} \mathrm{NaCl})$. After the treatment with the primary antibodies has been completed, the antigen-antibody complexes were detected with a peroxidase-conjugated polymer that carries secondary antibody molecules directed against mouse immunoglobulins for HSP70 and HSP90 or against rabbit immunoglobulins for caspase-3 (EnVisionTM+, DakoCytomation Denmark A/S, Glostrup, Denmark) applied for $120 \mathrm{~min}$ at room temperature. Peroxidase activity was then detected with diaminobenzidine (DAB, DakoCytomation Denmark A/S) as the substrate. Appropriate 
washing with TBS was performed between each step, and all incubations were carried out in a moist chamber. All sections were finally weakly counterstained with Mayer's haematoxylin, dehydrated, and permanently mounted. The specificity tests for the used antibodies were performed by incubating other sections in parallel with: i) TBS instead of the specific primary antibodies; ii) TBS instead of the secondary antibodies. The results of these controls were always negative (i.e., staining was abolished). Photomicrographs were taken with an Olympus BX51 microscope equipped with a digital camera, and final magnifications were calculated.

PCNA-immunopositive cells were for brevity described as "proliferating cells" and their relative cell number was evaluated by counting the muscle fibres immunopositive nuclei in a tissue area corresponding to the above mentioned FMA at the three analysed developmental stages and then converted to number of proliferating cells $/ \mathrm{mm}^{2}$.

\section{Statistical analysis}

Statistical analysis was performed with SAS statistical software (ver. 9.3, Cary, NC, USA). Data from the histometrical analyses (TMA, SMA and FMA) and PCNA cellular counts, were analysed using 2-way ANOVA with temperatures $\left(16^{\circ} \mathrm{C}, 19^{\circ} \mathrm{C}, 22^{\circ} \mathrm{C}\right)$ and developmental stages (T0, T1 and $\mathrm{T} 2$ ) as main factors, and co-variated for the total area corresponding to the TMA. The data are presented as least-square means (LSM) with standard errors. Differences between means were considered significant at $\mathrm{P}<0.05$.

\section{Results}

\section{Larval development}

The higher the temperature, the shorter was larvae development (Figure 1). Larvae subjected to $22^{\circ} \mathrm{C}$, presented the schooling behaviour at $3 \mathrm{dph}$ and at $7 \mathrm{dph}$ the yolk-sac was fully absorbed; larvae subjected to both $16^{\circ} \mathrm{C}$ and $19^{\circ} \mathrm{C}$ reached the schooling stage $5 \mathrm{dph}$ but larvae subjected to $19^{\circ} \mathrm{C}$ showed a faster absorption of the yolk-sac when compared with larvae subjected to $16^{\circ} \mathrm{C}$.

\section{Histometry and histochemistry}

HE staining results are presented in Figure 2. At hatching (T0; Figure $2 \mathrm{a}, \mathrm{h}$ ), the lateral muscle was already organised in an internal (Figure 2h, bold arrow) as well a peripheral layer (Figure $2 \mathrm{~h}$, thin arrow). At T1 (Figure 2 b-d,i), the transversally sec- tioned myotomes appeared composed of a layer of internal dorso-ventrally flattened lamella-shaped multinucleated muscle cells (future fast fibres; Figure 2i, asterisk). The nuclei were present in a central position in muscle cells. At this stage, there was a relevant expansion of the myotome at mediumlateral and dorsal-ventral levels, in comparison with previously, as a result of the addition of new developing fibres (Figure $2 \mathrm{~b}$-d; bold arrows). Most of the new generated fibres of the myotome were observed within the prospective fast muscle area, in such a way that the medial row of lamella-shaped fibres appeared overlaid laterally by a 3-4 layer bulk of smaller polygonal cells (Figure 2i, hexagon), which extended towards both dorsal and ventral parts. The prospective slow fibres at the periphery of the myotome have been shown to maintain a monolayer arrangement (Figure 2 b-d, thin arrow) with only a few additional muscle precursor cells (MPCs), mostly located at the medial edge of the layer. The myotomes did not show at this stage any anatomical separation between their dorsal and ventral domains. There was still no evidence of any vascularisation of the myotome area (Figure $2 \mathrm{~b}-\mathrm{d}$ ). The increase of the total muscle cross sectional area from hatching to the schooling phase was due mainly to an increase of the fast muscle cross sectional area: in only 3 to 5 days the fast muscle cross sectional area increased 11 times while the slow fibres area increased only 2.5 times (Figure $2 \mathrm{e}-\mathrm{g}$; thin arrows).

When the yolk-sac was fully absorbed (T2), the myotomes did not show any relevant difference in their structure compared to the schooling phase (T1), except for the further enlargement of the prospective fast muscle cross sectional area (Figure $2 \mathrm{e}-\mathrm{g}$; bold arrows; Figure 2j).

Histometry revealed that both TMA and
FMA were larger in the schooling phase at $19^{\circ} \mathrm{C}$ (Figure $2 \mathrm{k}, \mathrm{m} ; 19^{\circ} \mathrm{C}$ vs $16^{\circ} \mathrm{C}, \mathrm{P}<0.01$; $19^{\circ} \mathrm{C}$ vs $22^{\circ} \mathrm{C}, \mathrm{P}<0.05$ ), while no differences were observed in SMA at any of the tested rearing temperatures $(\mathrm{P}>0.05$ all comparisons, Figure 21).

Masson's Goldner Trichrome histochemistry confirmed the histological observations concerning the different areas occupied by the prospective slow and fast muscle fibres and the absence of a horizontal septum (Figure 3 a-g, asterisk).

\section{Immunohistochemistry and cell counts}

Anti-PCNA immunohistochemistry showed at T0 a consistent number of immunopositive nuclei in both layers of the developing lateral muscle area, but mainly in the inner layer (Figure 4a). At both T1 and T2 stages (Figure $4 \mathrm{~b}-\mathrm{d}$ and $\mathrm{f}-\mathrm{h}$, respectively) several nuclei of muscle prospective fast fibres in all the experimental groups were shown to be immunoreactive (thin arrows), while the prospective slow fibres nuclei revealed to be always negative (asterisks). An additional and representative record was the presence of immunopositivity in some neuroblast nuclei of the neural tube (Figure 4f, bold arrows). Quantitative evaluation of the proliferating prospective fast muscle cells (FMA) revealed that in the T0 group was significantly higher than all the other groups (Figure $4 \mathrm{e} ; \mathrm{P}<0.001$ ). In the T2 group a significantly higher number of proliferating cells was detected at $22^{\circ} \mathrm{C}$ reared larvae than in those ones reared at $16^{\circ} \mathrm{C}$ (Figure $4 \mathrm{e}, \mathrm{P}<0.05$ ). The anti-caspase immunohistochemistry was never detected in the larvae irrespective of the temperatures, except for the presence of small groups of immunoreactive cells in the epithelial layer of the yolk sac and of the developing alimentary canal (data not shown).

A HSP70-immunopositivity was never

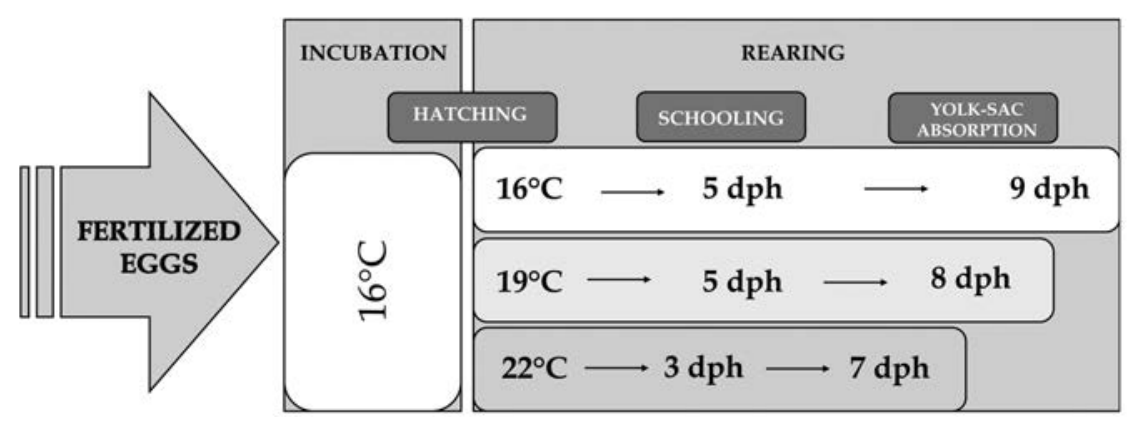

Figure 1. Experimental set-up. dph, days post-hatch. 
observed in the developing lateral muscle, irrespective of the different analysed rearing temperatures (data not shown). On the contrary, a HSP90 immunopositivity was clearly detected in a large number of nuclei of the prospective muscle fast fibres, mainly in larvae subjected to $19^{\circ} \mathrm{C}$ (Figure 5 a-g; asterisks) and in the neuroblasts (Figure 5 a$\mathrm{g}$, thin arrows).

\section{Discussion}

The present work investigated the impact of different rearing temperatures on muscle development of precocious (yolk sac) Siberian sturgeon larvae. Three rearing temperatures $\left(16,19\right.$ or $\left.22^{\circ} \mathrm{C}\right)$ were tested during Siberian sturgeon endogenous feeding larval phase, in order to analyse the short-term effect of temperature on the developing lateral muscle.
Temperature effects on developmental rate and survival

Temperature is one of the most important environmental factors that affect development and growth in teleost fishes, ${ }^{22,23}$ and the larval phase is particularly susceptible to temperature changes..$^{24,25}$ In the present study the time interval, during which larvae subjected to the highest rearing temperature $\left(22^{\circ} \mathrm{C}\right)$ reached the complete yolk-sac absorption stage was numerically $20 \%$ less

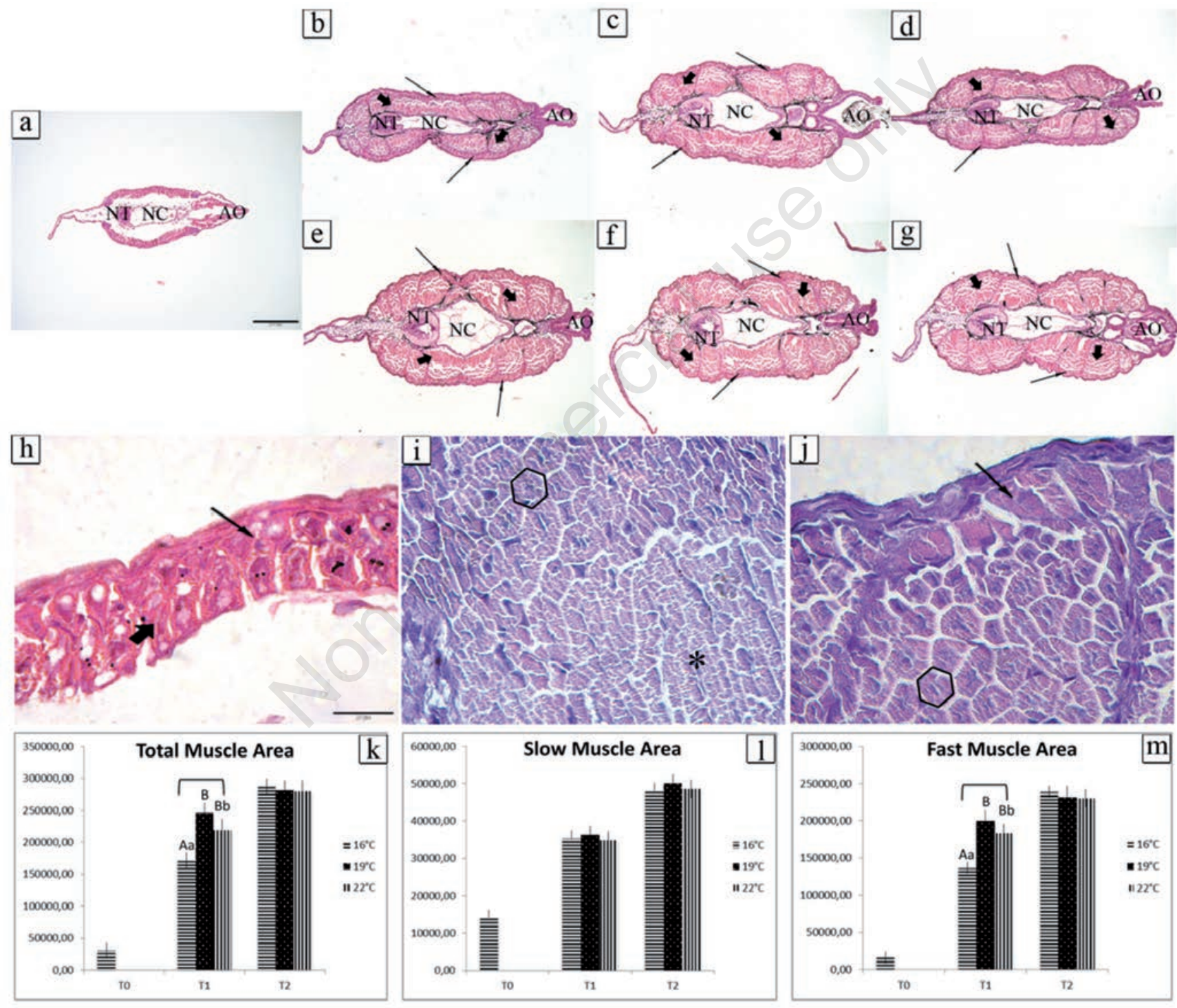

Figure 2. Images of the three temperatures at different timepoints - HE staining. a) At hatching, $16^{\circ} \mathrm{C}$; b-d) at schooling, at 16,19 and $22^{\circ} \mathrm{C}$, respectively; e-g) yolk-sac full absorption, at 16,19 and $22^{\circ} \mathrm{C}$, respectively; thin arrows, slow fibres; bold arrows, fast fibres; $\mathrm{NC}$, notochord; NT, neural tube; AO, anal opening; scale bars: a-g) $200 \mu \mathrm{m}$; h-j) HE staining representative figures for hatching, schooling

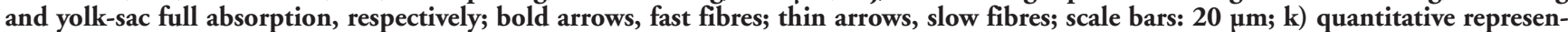
tation of TMA: area expressed in $\mu^{2} ; n=9$ /group; stage $P<0.001$; temp. $P<0.001$; stage*temp. $P<0.001$; 1$)$ quantitative representation of SMA: area expressed in $\mu^{2}$; $n=9$ /group; stage $P<0.001$; temp. $P=0.669$; stage*temp. $P=0.954$; m) quantitative representation of FMA: area expressed in $\mu^{2}{ }^{2} ; n=9 /$ group; stage $P<0.001$; temp. $P<0.001$; stage temp. $P<0.001$. 
than the time required by larvae subjected to the lowest temperatures. Similarly, an increase of rearing temperatures (but within the physiological range) lead to an increase in the developmental rate in several marine species like cod, ${ }^{26}$ Senegalese sole, ${ }^{27}$ and gilthead sea bream, ${ }^{28}$ as well as in freshwater species like brown trout, ${ }^{29}$ Atlantic salmon, ${ }^{30}$ and in several species of sturgeon. ${ }^{31}$ Moreover, it is also known that temperature can be associated with fish survival rates. ${ }^{32}$ In fact, in studies conducted upon different sturgeon species a clear effect of temperature on survival to hatch was shown, ${ }^{33,34}$ whereas during the endoge- nous feeding stage temperature did not influence survival rates until the complete yolk-sac absorption. ${ }^{32,35}$ In our study, survival rates from hatch to the complete yolksac absorption varied between 88 and $90 \%$ but there were no significant differences among tested rearing temperatures, which is in accordance with the above mentioned studies.

\section{Different temperatures and early events in myogenesis}

Our results showed that since the hatching phase it was already possible to identify in $A$. baerii a superficial monolayer of prospective slow fibres and a deep layer of prospective fast fibres. In addition, with the development going on until the yolk-sac full absorption stage, the inner layer of prospective fast fibres becomes larger and larger likely through the recruitment of MPCs. The tested rearing temperatures did not show effects upon the described arrangement.

The horizontal septum is a specialized structure of the myotome, present in all gnathostome fishes, that divide the differentiating myotomes into dorsal and ventral muscle masses. ${ }^{36}$ In our study we found

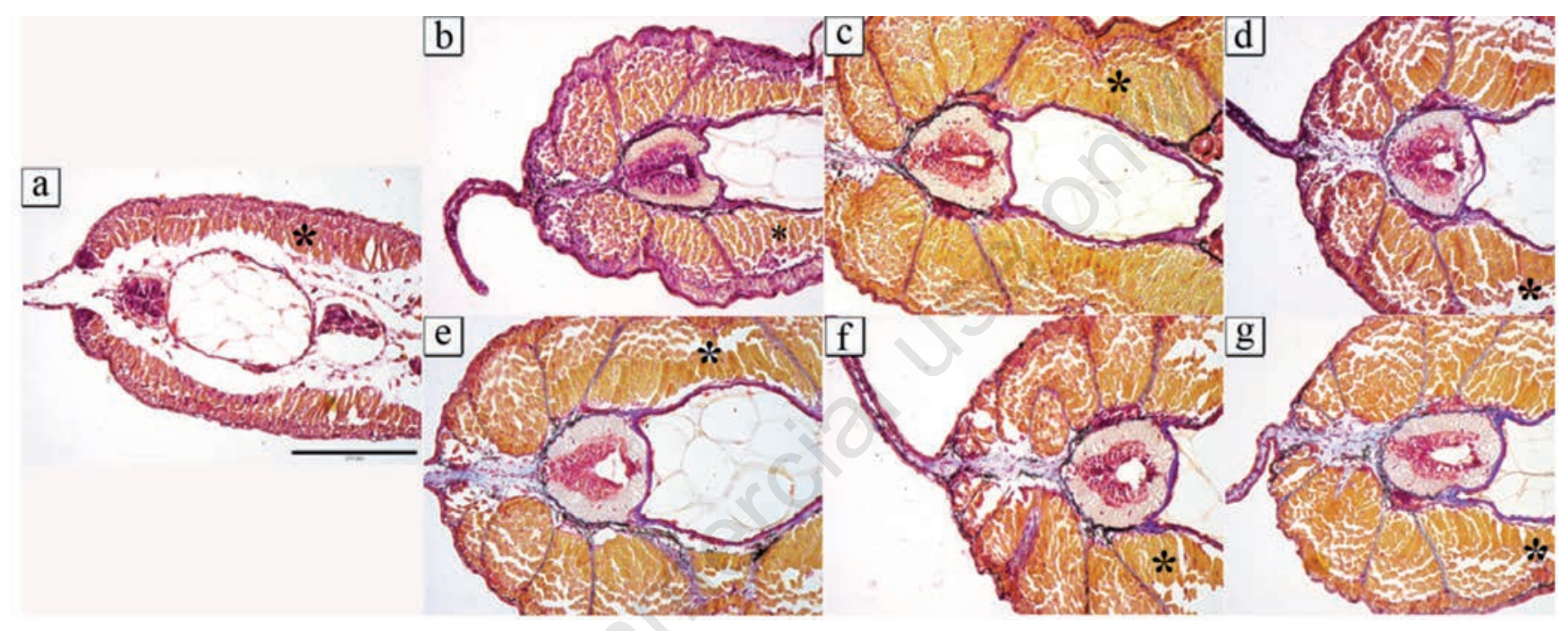

Figure 3. Images of the three temperatures at different timepoints - Masson's Trichrome Goldner staining. a) Hatching at $16^{\circ} \mathrm{C}$; b-d) schooling, at 16,19 and $22^{\circ} \mathrm{C}$, respectively; e-g) yolk-sac full absorption at 16,19 and $22^{\circ} \mathrm{C}$, respectively; asterisks, lack of horizontal septum. Scale bar: $200 \mu \mathrm{m}$.

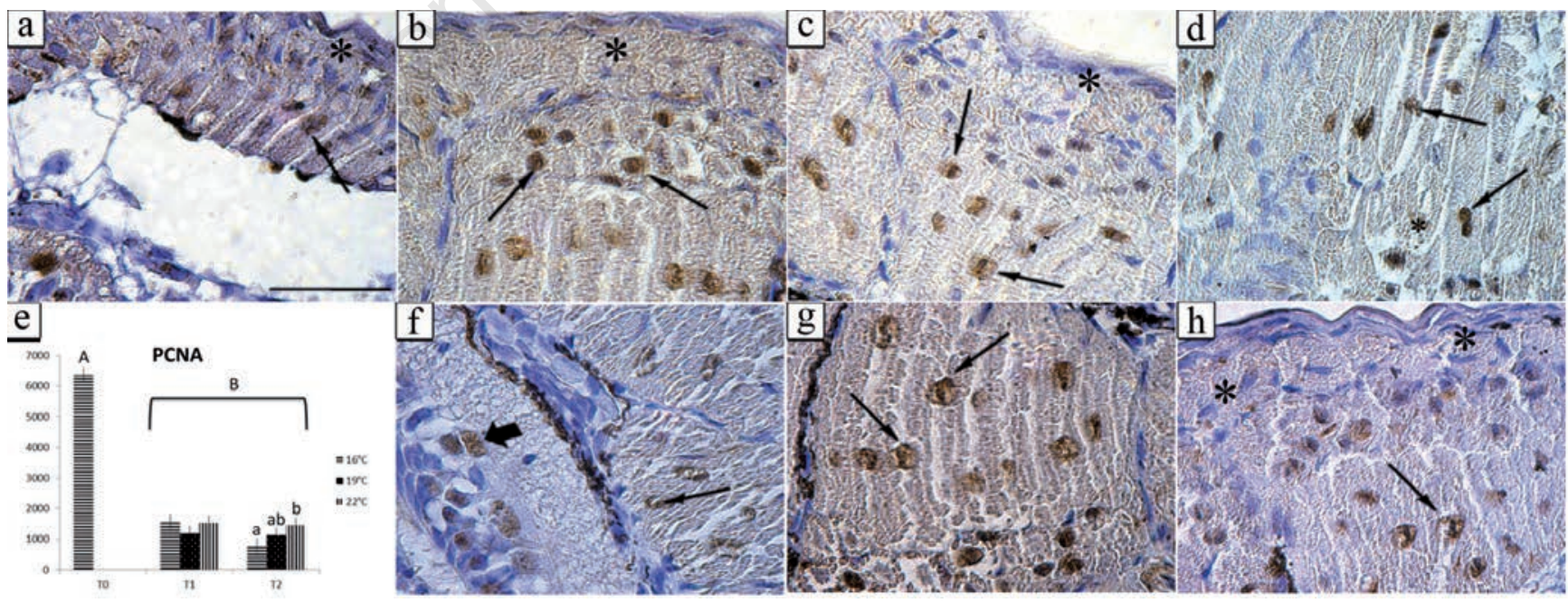

Figure 4. Images of the three temperatures at different timepoints - PCNA-immunolocalization. a) Hatching at $16^{\circ} \mathrm{C}$; b-d) schooling at 16,19 and $22^{\circ} \mathrm{C}$, respectively; f-h) yolk-sac full absorption at 16,19 and $22^{\circ} \mathrm{C}$, respectively; bold arrow, immunopositive neuroblasts; thin arrows, immunopositive nuclei in the fast fibres; asterisks, immunonegative slow fibres; scale bar: $20 \mu \mathrm{m}$; e) quantitative representation of PCNA counts; area expressed in number $/ \mathrm{mm}^{2}$; $n=9 /$ group; stage $P<0.001$; temp. $P=0.711$; stage*temp. $P=0.611$. 
that, until the end of the trial, yolk-sac larvae showed no clear separation between the dorsal and ventral components of the myotomes. This is in accordance with a study on sterlet, where the formation of such septum occurred only 14 days after hatching, suggesting that physical factors such as mechanical strain from initial swimming movements are necessary for the development of this structure. ${ }^{37}$ In comparison, in teleost fish the horizontal septum appears well defined already in the embryo. ${ }^{37-39}$ This aspect constitutes a major difference between teleosts and sturgeons.

\section{Different temperatures and lateral muscle histometry}

Muscle growth in fish has been extensively studied mainly in teleosts, mostly in intensively farmed species. In our study, we measured in serial transverse sections the total cross sectional muscle area, the prospective slow muscle cross sectional area and the prospective fast muscle cross sectional area at three specific stages of development: hatching, schooling, and full yolk-sac absorption. We found that total muscle cross sectional area and fast muscle cross sectional area were significantly larger at schooling stage for larvae subjected to the rearing temperature of $19^{\circ} \mathrm{C}$. This difference was not significant at the yolk-sac absorption stage, where larvae subjected to $16^{\circ} \mathrm{C}$ as the applied incubation temperature seemed to have recovered both in terms of total muscle cross sectional area and in fast muscle cross sectional area. On the contrary, the slow muscle area was not affected by temperature at any stage of development. These data remain unclear and should be further investigated.

\section{Proliferating cells}

In teleosts, skeletal muscle growth is the result of two processes: hypertrophy (increase in fibre size) combined with hyperplasia (formation of new fibres), both stratified and mosaic in types, often in temporal succession. ${ }^{40}$ Taking into account the lamellar shape of the prospective muscle fast fibres, we applied, according to Veggetti et al., ${ }^{41}$ PCNA-immunohistochemistry in order to detect the possibly occurring hyperplastic growth in this muscle area. PCNA-immunoreative nuclei were detected in cells of the deep layer of the developing muscle layer since hatching, but in both schooling and yolk-sac absorption stages PCNA-immunoreactive nuclei were only detected in prospective fast fibres, with a significant increment of proliferating cells between $16^{\circ} \mathrm{C}$ - and $22^{\circ} \mathrm{C}$-reared larvae in T2 group. The PCNA-immunoreactive nuclei of prospective slow fibres layer were scarce, in all the applied temperatures and stages of development, which is in accordance with the findings of Daczewska and Saczko. ${ }^{42}$ Similarly to what observed by Daczewska and Saczko ${ }^{42}$ again, we can at this moment conclude that, limited to the observed precocious development stages, the growth of the developing lateral muscle of $A$. baerii is based upon both hypertrophic and hyperplastic mechanisms that however concerns the prospective fast muscle cross sectional area only. Anti-PCNA cell counts showed higher proliferation in larvae subjected to $22^{\circ} \mathrm{C}$ than $16^{\circ} \mathrm{C}$, thus indicating a hyperplastic mechanism at $22^{\circ} \mathrm{C}$ even if limited to the yolk-sac absorption phase, whereas the hypertrophic one appeared influenced by the temperature of $19^{\circ} \mathrm{C}$ at schooling stage, an aspect which deserves further studies.

\section{Apoptotic cells}

A cellular turnover cannot at present be identified because apoptotic nuclei, identifiable applying anti-caspase immunoreactivity, have never been detected in the developing lateral muscle, likely due to the precocity of the studied developmental stages, in which proliferating cells only have been observed. Apoptosis is reputed a fundamental process during fish development and may be influenced by altered environmental factors such as salinity, $\mathrm{pH}$, oxygen consumption, UV radiation, as well as temperature, in such a way to be eventually responsible of deformities and abnormalities. ${ }^{43}$ It is in addition to underline that the absence of apoptotic cells in the developing lateral muscle is a demonstration that the experimentally applied rearing temperatures are not detrimental for the development of $A$. baerii.

\section{Heat-shock proteins 70 and 90}

In this study we have investigated the presence and cellular localization, as immunohistochemically expressed, of both HSP70 and HSP90, considering that they constitute the most frequently described HSP families in vertebrates including fish

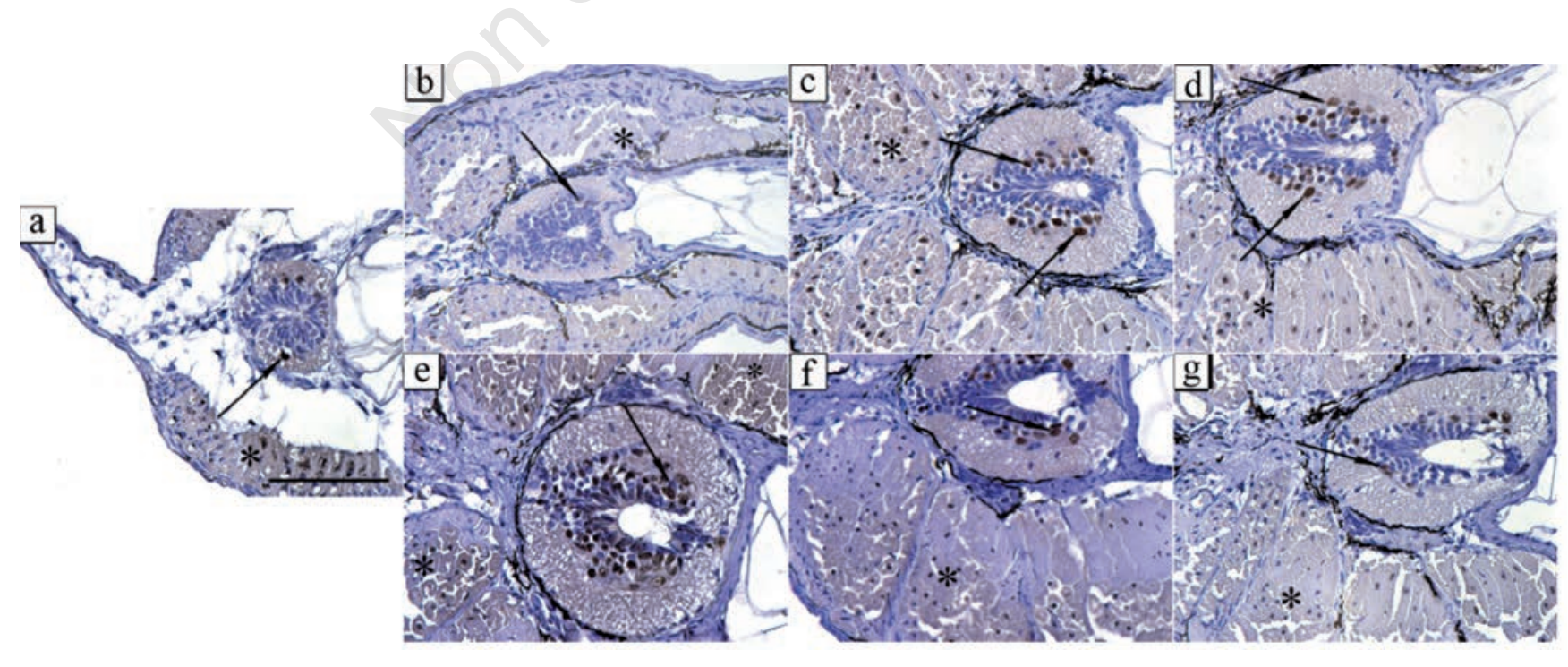

Figure 5. Images of the three temperatures at different timepoints - HSP90-immunolocalization. a) $\mathrm{Hatching}$ at $16^{\circ} \mathrm{C}$; b-d) schooling, at 16,19 and $22^{\circ} \mathrm{C}$, respectively; e-g) yolk-sac full absorption at 16,19 and $22^{\circ} \mathrm{C}$, respectively; thin arrows, immunopositive neuroblasts; asterisks, immunopositive fast fibres. Scale bar: $100 \mu \mathrm{m}$. 
species. ${ }^{44-47}$ HSP70 was never identified by us in the examined precocious sturgeon larvae: this observation appears in full accordance with the part of the study by Rupik et $a l .{ }^{45}$ referring to zebrafish embryos, in which the absence of HSP70 expression has been described in concomitance with physiological temperatures in the environment. In comparison, in studies conducted in various species, including Acipenseridae, there was always evidence of an increase of HSP synthesis as a consequence of a thermal stress. ${ }^{47-54}$ In addition, studies conducted in other fish species showed the expression of HSP70 linked to the occurrence of transport stress. ${ }^{55,56}$ As a preliminary consequence, we can suggest that all the experimentally applied temperatures, not accompanied by a HSP70 expression, are to be considered within the physiological range for this species and for the studied stages.

On the contrary, a HSP90 immunoreactivity was clearly identified in nuclei of the prospective fast muscle fibres as well as in nuclei of the developing grey matter of the neural tube, particularly evident at $19^{\circ} \mathrm{C}$. These observations are to be related to a regulative function in myofibrillogenesis attributed to HSP90 during the development of zebrafish, as well to the synthesis of regulatory proteins such as steroid hormone receptors. ${ }^{45}$ This part of our study enabled us to demonstrate that all the three applied experimental temperatures are accompanied by the expression of HSP90 in the developing lateral muscle, where the protein can likely display its multiple chaperon molecule functions. The immunoreactivity was especially intense at $19^{\circ} \mathrm{C}$. Interestingly, this latter rearing temperature is the same, in which we have here showed larger dimensions of both total muscle area and prospective fast muscle area via the hypertrophy mechanism.

In conclusion, even considering that all the three experimental rearing temperatures are congruent with a correct development of cultured $A$. baerii and that a rearing temperature of $22^{\circ} \mathrm{C}$ leads to a higher developmental rate of $A$. baerii larvae (which could be advantageous in commercial hatcheries), we can at present conclude that a temperature of $19^{\circ} \mathrm{C}$ can support larger size in developing larvae and likely a speedy acquisition of swimming capacities. Further studies are however necessary in order to investigate the expression of genes involved in the lateral muscle development in Siberian sturgeon yolk-sac larvae, with the additional aim to investigate the possible disjunction between HSP70 mRNA and measurable HSP70 tissue levels.

\section{References}

1. Birnstein VJ. Sturgeon and paddlefishes: threatened fishes in need of conservation. Conserv Biol 1993;7:773-87.

2. Leprevost A, Azais T, Trichet M, Sire JI. Vertebral development and ossification in the Siberian sturgeon (Acipenser baerii), with new insights on bone histology and ultrastructure of vertebral elements and scutes. Anat Rec 2017; 300:437-49.

3. Conceicao L, Aragao C, Richard N, Engrola S, Gavaia P, Mira S. Novel methodologies in marine fish larval nutrition. Fish Physiol Biochem 2010; 36:1-16.

4. Mohler JW, King MK, Farrel PR. Growth and survival of first-feeding and fingerling Atlantic sturgeon under culture conditions. N Am J Aquac 2000; 62:174-83.

5. Lushchak VI. Environmentally induced oxidative stress in aquatic animals. Aquat Toxicol 2011;101:13-30.

6. Domeneghini C, Radaelli G, Bosi G, Arrighi S, Di Giancamillo A, Pazzaglia $\mathrm{M}$, et al. Morphological and histochemical differences in the structure of the alimentary canal in feeding and runt (feed deprived) white sturgeons (Acipenser transmontanus). J Appl Ichthyol 2002;18:341-6.

7. Di Giancamillo A, Martino PA, Arrighi S, Domeneghini C. Gut Peculiarities of feed deprived white sturgeons (Acipenser transmontanus, Richardson 1836). Open J Vet Med 2012;2:52-9.

8. Feder ME, Hofmann GE. Heat-shock proteins, molecular chaperones, and the stress response: evolutionary and ecological physiology. Annu Rev Physiol 1999;61:243-82.

9. Roberts RJ, Agius C, Saliba C, Bossier $\mathrm{P}$, Sung YY. Heat shock proteins (chaperones) in fish and shellfish and their potential role in relation to fish health: a review. J Fish Dis 2010;33:789-801.

10. Roy S, Bhattacharya S. Arsenic-induced histopathology and synthesis of stress proteins in liver and kidney of Channa punctatus. J Fish Dis 2006;65:218-29.

11. Eder KJ, Köhler HR, Werner J. Pesticide and pathogen: heat shock protein expression and acetylcholinesterase inhibition in juvenile Chinook salmon in response to multiple stressors. Environ Toxicol Chem 2007;26:123342.

12. Maradonna F, Carnevali O. Vitellogenin, zona radiate protein, cathepsin D and heat shock protein 70 as biomarkers of response to xenobi- otics. Biomarkers 2007;12:240-55.

13. Pederzoli A, Mola L. The early stress responses in fish larvae. Acta Histochem 2016;118:443-9.

14. Stefanovich DI, Manzon LA, McDougall CS, Boreham DR, Somers CM, Wilson JY, et al. Thermal stress and the heat shock response in embryonic and young adult of the year juvenile lake whitefish. Comp Biochem Physiol Part A 2016;193:1-10.

15. Gisbert E, Williot P. Duration of synchronous egg cleavage cycles at different temperatures in Siberian sturgeon (Acipenser baerii). J Appl Ichthyol 2002;18:271-4.

16. Zitov RE, Millard JL. Survival and growth of lake withefish (Coregonus clupeaformis) larvae fed only formulated dry diets. Aquaculture 1988;69:10513.

17. Gisbert E, Williot P, Castelló-Orvay, F. Behavioural modifications in the early life stages of Siberian sturgeon (Acipenser baeri, Brandt). J Appl Ichthyol 1999;15:237-42.

18. Rehfeldt C, Te Pas MFW, Wimmers K, Brameld JM, Nissen PM, Berri C. Advances in research on the prenatal development of skeletal muscle in animals in relation to the quality of muscle-based food. I. Regulation of myogenesis and environmental impact. Animal 2011;5:718-30.

19. Goldner J. A modification of the Masson trichrome technique. Am J Pathol 1938;14:247-9.

20. Di Giancamillo A, Rossi R, Vitari F, Pastorelli G, Corino C, Domeneghini C. Dietary conjugated linoleic acids decrease leptin in porcine adipose tissue. J Nutr 2009;139:1867-72.

21. Di Giancamillo A, Rossi R, Pastorelli G, Deponti D, Carollo V, Casamassima $\mathrm{D}$, et al. The effects of dietary verbascoside on blood and liver oxidative stress status induced by a high n-6 polyunsaturated fatty acids diet in piglets. J Anim Sci 2015;93:2849-59.

22. Moyle PB, Cech JJJR. Fishes: An introduction to ichthyology. London: Prentice Hall; 1982.

23. Donaldson MR, Cooke SJ, Patterson DA, MacDonald JS. Cold shock and fish. J Fish Biol 2008;73:1491-530.

24. Johnston I, Vieira V, Abercromby M. Temperature and myogenesis in embryos of the Atlantic herring Clupea harengus. J Exp Biol 1995;198:1389403.

25. Kamler E. Ontogeny of yolk-feeding fish: an ecological perspective. Rev Fish Biol Fish 2002;12:79-103. 
26. Pepin P, Orr DC, Anderson JT. Time to hatch and larval size in relation to temperature and egg size in Atlantic cod (Gadus morhua). Can J Fish Aquat Sci 1997;54:2-10.

27. Campos C, Fernandes JMO, Conceição LEC, Engrola S, Sousa V, Valente LMP. Thermal conditions during larval pelagic phase influence subsequent somatic growth of Senegalese sole by modulating gene expression and muscle growth dynamics. Aquaculture 2013;414415:46-55.

28. Garcia de la Serrana D, Vieira VLA, Andree KB, Darias M, Estévez A, Gisbert E, et al. Development Temperature has persistent effects on muscle growth responses in gilthead sea bream. PLoS One 2012;7:e51884.

29. Réalis-Doyelle E, Pasquet A, De Charleroy D, Fontaine P, Teletchea F. Strong effects of temperature on the early life stages of a cold stenothermal fish species, brown trout (Salmo trutta L.). PLoS One 2016;11:e155487.

30. Ojanguren AF, Reyes-Gavilán FG, Muñoz RR. Effects of temperature on growth and efficiency of yolk utilisation in eggs and pre-feeding larval stages of Atlantic salmon. Aquacult Int 1999; 7:81.

31. Hardy RS, Litvak MK. Effects of Temperature on the early development, growth, and survival of shortnose sturgeon, Acipenser brevirostrum, and Atlantic sturgeon, Acipenser oxyrhynchus, yolk-sac larvae. Environ Biol Fishes 2004;70:145.

32. Boucher MA, McAdam SO, Shrimpton JM. The effect of temperature and substrate on the growth, development and survival of larval white sturgeon. Aquaculture 2014;430:139-48.

33. Wang YL, Buddington RK, Doroshov SI. Influence of temperature on yolk utilization by the white sturgeon, Acipenser transmontanus. J Fish Biol 1987;30:263-71.

34. Van Eenennaam JP, Linares-Casenave J, Deng X, Doroshov SI. Effect of incubation temperature on green sturgeons embryos, Acipenser medirostris. Environ Biol Fishes 2005;72:145-54.

35. Gisbert E, Williot P, Castelló-Orvay F. Influence of egg size on growth and survival of early stages of Siberian sturgeon (Acipenser baerii) under small scale hatchery conditions. Aquaculture 2000;183:83-94.

36. Bone Q. Evolutionary patterns of axial muscle systems in some invertebrates and fish. Integr Comp Biol 1989;29:5-18. 37. Steinbacher P, Haslett JR, Sänger AM, Stoiber W. Evolution of myogenesis in fish: a sturgeon view of the mechanisms of muscle development. Anat Embryol 2006;211:311-22.

38. Currie PD, Ingham PW. Induction and patterning of embryonic skeletal muscle cells in zebrafish. In: Johnston IA, editor. Muscle development and growth. San Diego: Academic Press; 2001. p. 1-17.

39. Chauvigné F, Ralliere C, Cauty C, Rescan PY. In situ hybridisation of a large repertoire of muscle-specific transcripts in fish larvae: the new superficial slow-twitch fibres exhibit characteristics of fast-twitch differentiation. J Exp Biol 2006;209:372-9.

40. Rowlerson A, Vegetti A. Cellular mechanism of post-embryonic muscle growth in aquaculture species. In: Johnston IA, editor. Muscle development and growth. San Diego: Academic Press; 2001. p. 103-140.

41. Veggetti A, Rowlerson A, Radaelli G, Arrighi S, Domeneghini C. Post-hatching development of the gut and lateral muscle in the sole. J Fish Biol 1999; 55(Suppl A):44-65.

42. Daczewska M, Saczko J. Myotomal myogenesis of axial muscle in the sturgeon Acipenser baeri (Chondrostei, Acipenseriformes). Folia Biol (Kraków) 2005;53:29-38.

43. AnvariFar H, Amirkolaie AK, Miandare HG, Ouraji H, Jalali MJ, Üçüncü SI. Apoptosis in fish: environmental factors and programmed cell death. Cell Tissue Res 2016;68:425-39.

44. Deane EE, Woo NYS. Advances and perspectives on the regulation and expression of piscine heat shock proteins. Rev Fish Biol Fish 2010;21:153-85.

45. Rupik W, Jasik K, Bembenk J, Widlak W. The expression patterns of heat shock genes and proteins and their role during vertebrate's development. Comp Biochem Physiol Part A 2011;159:349-66.

46. Lewis M, Gotting M, Anttila K, Kanerva M, Prokkola JM, Seppanen E, et al. Different relationship between hsp70 mRNA and hsp70 levels in the heat shock response of two Salmonids with dissimilar temperature preference. Front Physiol 2016;7:511.

47. Peng G, Zhao W, Shi Z, Chen H, Liu Y, Wei J, et al. Cloning HSP70 and HSP90 genes of kaluga (Huso dauricus) and the effects of temperature and salinity stress on their gene expression. Cell Stress Chaperones. 2016;21:349-59.
48. Allen PJ, Hodge B, Werner I, Cech JJ Jr. Effects of ontogeny, season, and temperature on the swimming performance of juvenile green sturgeon (Acipenser medirostris). Can J Fish Aquat Sci 2006;63:1360-9.

49. Bertotto D, Poltronieri C, Negrato E, Richard J, Pascoli F, Simontacchi C, et al. Whole body cortisol and expression of HSP70, IGF-I and MSTN in early development of sea bass subjected to heat shock. Gen Comp Endocrinol 2011;174:44-50.

50. Han D, Huang SSY, Wang WF, Deng DF, Hung SSO. Starvation reduces the heat shock protein responses in white sturgeon larvae. Environ Biol Fishes 2012;93:333-42.

51. Linares-Casenave J, Werner I, Van Eenennaam JP, Doroshov SI. Temperature stress induces notochord abnormalities and heat shock proteins expression in larval green sturgeon (Acipenser medirostris Ayres 1854). J Appl Ichthyol 2013;29:958-67.

52. Zheng K, Wang W, Hung SSO, Deng DF. Feeding rates affect expression of heat-shock protein 70 in green sturgeon fry. N Am J Aquacult 2015;77:206-10.

53. He J, Wang J, Xu M, Wu C, Liu H. The cooperative expression of Heat Shock Protein 70KD and 9o KD gene in juvenile Larimichthys crocea under Vibrio alginolyticus stress. Fish Shellfish Immunol 2016;58:359-69.

54. Simide R, Richard S, Prévot-D'Alvise N, Miard T, Gaillard S. Assessment of the accuracy of physiological blood indicators for the evaluation of stress, health status and welfare in Siberian sturgeon (Acipenser baerii) subject to chronic heat stress and dietary supplementation. Int Aquat Res 2016;8:121-35.

55. Poltronieri C, Maccatrozzo L, Simontacchi C, Bertotto D, Funkenstein B, Radaelli G. Quantitative TR-PCR analysis and immunohistochemical localization of HSP70 in sea bass Dicentrarchus labrax exposed to transport stress. Eur J Histochem 2007;51: 125-36.

56. Poltronieri C, Negrato E, Bertotto D, Majolini D, Simontacchi C, Radaelli G. Immunohistochemical localization of constitutive and inducible Heat Shock Protein 70 in carp (Cyprinus carpio) and trout (Oncorhynchus mykiss) exposed to transport stress. Eur J Histochem 2008;52:191-8. 